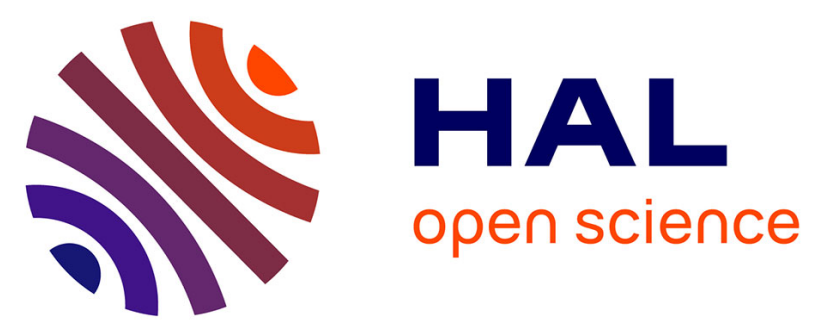

\title{
Multiscale modeling of crystal plasticity in Reactor Pressure Vesselsteels: Prediction of irradiation hardening
}

\author{
Ghiath Monnet, Ludovic Vincent, Lionel Gelebart
}

\section{To cite this version:}

Ghiath Monnet, Ludovic Vincent, Lionel Gelebart. Multiscale modeling of crystal plasticity in Reactor Pressure Vesselsteels: Prediction of irradiation hardening. Journal of Nuclear Materials, 2018, 514, pp.128-138. 10.1016/j.jnucmat.2018.11.0280022 • cea-02339869

\section{HAL Id: cea-02339869} https://hal-cea.archives-ouvertes.fr/cea-02339869

Submitted on 5 Nov 2019

HAL is a multi-disciplinary open access archive for the deposit and dissemination of scientific research documents, whether they are published or not. The documents may come from teaching and research institutions in France or abroad, or from public or private research centers.
L'archive ouverte pluridisciplinaire HAL, est destinée au dépôt et à la diffusion de documents scientifiques de niveau recherche, publiés ou non, émanant des établissements d'enseignement et de recherche français ou étrangers, des laboratoires publics ou privés. 


\title{
Prediction of the mechanical behavior of irradiated Reactor Pressure Vessel steels: multiscale modeling of crystal plasticity
}

\author{
Ghiath Monnet ${ }^{\mathrm{a}}$, Ludovic Vincent ${ }^{\mathrm{b}}$ and Lionel Gélébart ${ }^{\mathrm{b}}$
}

${ }^{a}$ EDF - R\&D, MMC, avenue des Renardières, 77818 Moret sur Loing, France. Tel: +33160736473, Email: ghiath.monnet@edf.fr

${ }^{\mathrm{b}}$ DEN-Service de Recherches Métallurgiques Appliquées (SRMA), CEA, Université ParisSaclay, F-91191 Gif-sur-Yvette, France.

\begin{abstract}
In this paper, we present a set of equations capitalizing the multiscale modeling of the mechanical behavior of Reactor Pressure Vessel (RPV) steels before and after irradiation. The equations capture the temperature and strain rate sensitivity in addition to the contributions of microstructure features peculiar to RPV steels, such as carbides, initial dislocation network and the Hall-Petch grain size sensitivity. Dislocations are assumed to move on the $\{110\}$ and $\{112\}$ crystallographic planes and a simplified interaction matrix is proposed. The predicted yield stress is found in close agreement with a large number of experimental results over a large temperature range. Finally, contribution of radiation defects is accounted for using atomistic and dislocation dynamics results, revealing the effect of the solute cluster size and density on the mechanical behavior. Results are discussed and compared with an experimental database on neutron-irradiated RPV steels.
\end{abstract}

\section{Introduction}

Recently, a complete set of constitutive equations has been proposed to predict crystal plasticity in pure iron [1]. These equations, forming a so-called Crystalline Law (CL), are well-adapted for the prediction of the local behavior of ferrite in macroscopic modeling through homogenization techniques (full-field or self-consistent methods). The reported CL [1] accounted for the activation of 12 slip systems on the $\{110\}$ planes, the Burgers vectors being $1 / 2<111>$. The significant breakthrough of this CL was the proposal of a thermally activated rate equation, based on the analysis of Dislocation Dynamics (DD) results [2,3]. Hence, by accounting for the curvature of non-screw dislocations, it was shown that hardening induced by local obstacles (such as junctions and precipitates) decreases substantially with decreasing temperature. The line tension contribution to strain hardening was also found to increase with temperature and with density of local obstacles (dislocation network, carbides, etc) and to reach a plateau beyond a given temperature close to $400 \mathrm{~K}$ defining a so-called athermal regime. The line tension contribution appears only when the average length of screw dislocation segments decreases to a minimum critical value. In the athermal regime, where dislocation mobility is no longer controlled by lattice friction but by jog drag, a simpler CL can be used [4]. Another important contribution of the CL proposed in [1] was the proposition for a smooth transition between the two regimes (thermally activated vs athermal) through a harmonic superposition of the two rate equations, which assumes that the applied stress must provide at the same time enough nucleation rate of kink-pairs (controlling the low temperature flow) and sufficient driving force for the jog-dragged 
dislocations to pass through the local obstacle field. In other terms, the harmonic superposition rule is conservative.

Nevertheless, this CL cannot be applied directly to Reactor Pressure Vessel (RPV) steels, because other ingredients must be implemented, owing to the specific features of the bainitic microstructure. For more metallurgical details on the bainitic microstructure, readers are invited to consult the excellent textbook in ref [5]. The design and fabrication of RPV steels have recently been reviewed [6]. These materials experience significant radiation embrittlement due to the accumulation of radiation-induced defects of nanometric size. Although many phenomenological approaches for predicting radiation hardening were reported (see for ex. [7] and [8]), these approaches did not provide a global modeling of plastic deformation of irradiated RPV steels. Constitutive equations of the mechanical behavior are still missing. This is the main objective of the present paper.

The next chapter explains how the CL reported in [1] can be simplified and adapted to RPV steels, including the introduction of slip activity on the $\{112\}$ planes and of the grain size (Hall-Petch) effect on the flow stress. Chapter 3 presents a multiscale modeling of the radiation-induced hardening at the grain scale, accounting for the recent results of Molecular Dynamics (MD) and Dislocation Dynamics (DD) simulations. Chapter 4 is dedicated to the implementation of the CL in larger scale simulations (self-consistent and full-field methods) and to the presentation of simulation results. Finally the results are discussed and compared with experimental observations.

\section{Simplified crystalline law for irradiated RPV steels}

The objective of the construction of the CL reported in [1] was to reproduce plastic deformation in pure iron single crystal in details. The physical basis of the constitutive equations was recalled in details in [1]. It is not recalled here. To adapt this CL to RPV steels, different steps must be considered. First, when focusing on the behavior of polycrystals, not all details are relevant. Second, specific features of bainitic steels must be accounted for, such as solid solution and grain size effects. Third, when deforming polycrystals, grains of all orientations are involved. In this context, slip activity on the $\{112\}$ planes cannot be ignored. In the following, we present simple methods to take into account these modifications. For the sake of simplicity, the set of constitutive equations is introduced with the small strain approximation but can be extended straightforwardly to the finite strains framework [9].

\subsection{Rate equation}

The plastic slip rate on a reference slip system $s$ is a harmonic sum of the slip rates controlled by the jog-drag (noted by the lower index "drag") and lattice friction (lower index "friction"):

$\frac{1}{\dot{\gamma}^{s}}=\frac{1}{\dot{\gamma}_{\text {drag }}^{s}}+\frac{1}{\dot{\gamma}_{\text {friction }}^{s}}$.

By convention in this paper, upper indexes refer to the slip system number, while lower indexes denote the nature of the variable. For the sake of simplicity, the upper indexes may be omitted in the text, but not in the equations. The rate equation for the regime controlled by jog drag is given by:

$\dot{\gamma}_{\text {drag }}^{s}=\dot{\gamma}_{o}\left[\frac{\left|\tau_{a p p}^{s}\right|}{\tau_{c}^{s}}\right]^{n} \operatorname{sign}\left(\tau^{s}\right)$, 
where $\dot{\gamma}_{o}$ is a constant in the order of $10^{-5} \mathrm{~s}^{-1}, \tau_{\text {app }}$ is the resolved shear stress on the reference slip system, $\tau_{c}$ the critical stress (defined below). The shear rate in the lattice friction regime can be expressed as:

$\dot{\gamma}_{\text {friction }}^{s}=\rho_{m}^{s} b H l_{s c}^{s} \exp \left(-\frac{\Delta G_{o}}{k T}\left(1-\sqrt{\frac{\tau_{e f f}^{s}}{\tau_{o}^{s}}}\right)\right) \operatorname{sign}\left(\tau^{s}\right)$,

where $\rho_{m}$ is the mobile dislocation density (constant in our model), $b$ the norm of Burgers vector, $H$ a frequency factor, $l_{s c}^{s}$ is the average length of screw dislocation segments, $k$ the

Boltzmann constant, $T$ the absolute temperature, $\Delta G_{o}$ and $\tau_{o}$ two parameters fitted on experimental results. $\tau_{\text {eff }}$ is the effective stress, that is, the net driving force for dislocation motion. It is given by:

$$
\tau_{\text {eff }}^{s}= \begin{cases}\left|\tau_{\text {app }}^{s}\right|-\tau_{c}^{s} & \left|\tau_{\text {app }}^{s}\right| \geq \tau_{c}^{s} \\ 0 & \tau_{a p p} \leq \tau_{c}^{s}\end{cases}
$$

The absolute value of the applied stress is considered in order to assign the same sign for the applied stress and the shear stress.

\subsection{Average obstacle spacing}

As it will be seen in the next section, the computation of the critical stress $\tau_{c}$ requires the knowledge of the average length of screw segments $l_{s c}$, which is a function of the densities of local obstacles and their strengths. In the lower bainitic structure, local obstacles are lattice dislocations and intragranular carbides [5]. When irradiated, other defects appears in the matrix [10], basically Dislocation Loops (DLs) and Solute Clusters (SCs) considered as spherical precipitates in our model. According to the dispersed barrier hardening model [11] (cited by [12]), interaction statistics between moving dislocations and radiation-induced defects are controlled by the planner density of defects. For solute clusters we have $\rho_{S C}=$ $D_{S C} C_{S C}$, and $\rho_{D L}=D_{D L} C_{D L}$ for dislocation loops, where $D$ and $C$ are respectively the diameter and concentration of the defect family. Consequently, the total density of local obstacles in irradiated RPV steels can be given as:

$$
\rho_{o b s}^{s}=\sum_{j \neq s} \rho_{d i s}^{j}+\rho_{\text {carbide }}+\rho_{S C}+\rho_{D L},
$$

where $\rho_{\text {dis }}^{j}$ denotes dislocation density on slip system “ $j$ ". The sum in eq 14 is to be done over all slip systems (see next section). $\rho_{\text {carbides }}, \rho_{S C}$ and $\rho_{D L}$ are respectively the planner densities of carbides, solute clusters and dislocation loops. To this total obstacle density, one may associate an average obstacle strength on system s:

$$
\alpha^{s}=\frac{1}{\sqrt{\rho_{o b s}^{s}}} \sqrt{\sum_{j \neq s} a^{s j} \rho_{d i s}^{j}+a_{\text {carbide }} \rho_{\text {carbide }}+a_{S C} \rho_{S C}+a_{D L} \rho_{D L}},
$$

with $a^{s j}$ the interaction coefficient between slip systems $s$ and $j$, determined from DD simulations $[13,14]$. It is important to note here that the interaction coefficients with forest 
dislocations are note constant. The logarithmic correction [15] is necessary to account for the decrease in the dislocation line tension with the dislocation density. The following expression is used to update the values of the coefficients [16]:

$a^{s j}=\left(0.2+0.8 \frac{\ln \left(0.35 b \sqrt{\rho_{o b s}^{s}}\right)}{\ln \left(0.35 b \sqrt{\rho_{r e f}}\right)}\right)^{2} a_{r e f}^{s j}$

with the reference coefficients $a_{r e f}$ computed in DD simulations at the reference density $\rho_{r e f}=$ $10^{12} \mathrm{~m}^{-2}$ (see Figure 1).

The other interaction coefficients appearing under the square root in eq. 6 are determined using multiscale modeling, as will be shown in the next sections. Eq. 6 implies an implicit assumption about the superposition rule of strengthening sources. As discussed by Was [17], adding hardening contributions is not obvious. It depends on the nature and strength of the defects families. However, since all obstacles in eq. 6 are of local type, and since their planner density and stress contribution are comparable, the quadratic superposition rule seems to be the best choice. This has been demonstrated by DD simulations in the case of superposition of forest hardening and carbide strengthening [18]. For more details about this issue, readers are invited to consult the discussion reported in [19].

In the drag regime, dislocation mobility is isotropic and interaction statistic obeys the twodimensional Poisson's distribution leading to the well-known spacing of $1 / \sqrt{\rho_{o b s}}$. However, at low temperature, it has been shown [1] that interaction statistics follow the onedimensional Poisson's distribution, parallel to the Burgers vector. DD simulations [3] have shown that the low mobility of screw dislocations induces a curvature of non-screw dislocations in the order of $\frac{2 \tau_{e f f}}{\mu b}$, which leads to a curvature diameter:

$D^{s}=\frac{\mu b}{\tau_{\text {eff }}^{s}}$.

The one-dimensional distribution provides an average spacing close to $\left(D \rho_{o b s}\right)^{-1}$. With increasing temperature, the effective stress decreases and $D$ increases, such that $\left(D \rho_{o b s}\right)^{-1}$ exceeds the isotropic spacing $1 / \sqrt{\rho_{o b s}}$. To make a smooth transition between the two statistical distributions, one may consider the average spacing to be given by:

$\lambda^{s^{-1}}=\min \left\{\sqrt{\rho_{o b s}^{S}} ; D^{s} \rho_{o b s}^{s}\right\}$

Once the spacing is obtained, the average length of screw dislocation involved in eq. 3 can be given by [1]:

$l_{s c}^{s}=\max \left\{\lambda^{s}-\alpha^{s} D^{s} ; l_{c}\right\}$,

where $l_{c}$ is the minimum length of a screw dislocation segment, taken equal to $10 \mathrm{~nm}$.

\subsection{Critical stress}

The critical stress represents the athermal part of the flow stress. It accounts for different athermal contributions: the dipolar interaction $\tau_{\text {self }}$ (between dislocations belonging to the same slip system), the grain size or Hall-Petch (HP) effect $\tau_{H P}$ and the line tension $\tau_{L T}$. The athermal character of the Hall-Petch effect has been evidenced in many experimental 
observations [20,21]. Recently, Tsuchida et a. [22], have shown that grain size effect is also independent of strain rate. These observations indicate that this component must be added linearly to the other components of the critical stress. Solid solution hardening must also be added linearly as attested in other experimental results $[23,24]$, but it is expected to be much lower than the HP component. For the sake of simplicity we keep only one linear component accounting for the Hall-Petch effect and the solid solution, called $\tau_{H P}$. Consequently, the critical stress can be expressed as:

$\tau_{c}^{s}=\sqrt{\tau_{\text {self }}^{s}+\tau_{L T}^{s}{ }^{2}}+\tau_{H P}$

The self-interaction is given by the classical equation:

$\tau_{\text {self }}^{s}=\mu b \sqrt{a_{\text {self }} \rho^{s}}$

where $\mu$ is the shear modulus. The HPcomponent component is obtained by :

$$
\tau_{H P}=\frac{\mu}{\mu(300 K)} \frac{K}{\sqrt{d_{\text {grain }}}},
$$

where $d_{\text {grain }}$ is the grain size. In most models of the grain size effects, the HP constant $K$ is found proportional to the shear modulus. It is thus necessary to account for this dependency in our simulations. Since the experimentally determined values of $K$ were mostly determined at room temperature, eq. 13 allows using the so-obtained value at any simulation temperature. It is known that the HP effect depends on the crystallographic structure and the alloying elements in industrial materials $[25,26]$. For RPV steels, we believe that the appropriate value of $K$ is that reported by Tsuchida et al. [22 in the ferritic grains of the Fe-C system.

Concerning the line tension contribution, the assessment is not trivial. The reason is that straight screw dislocations are not always affected by the curvature of non-screw dislocation, as revealed in DD simulation [3]. Consequently, as long as screw dislocation segments are of finite size, that is $l_{s c}>l_{c}$, one can consider that there is no line tension contribution. But at high obstacle density and/or high temperature, $l_{s c}$ tends to $l_{c}$, and if the current curvature of non-screw dislocations at the vicinity of obstacles is not high enough to release dislocation segments from these obstacles, an increase of flow stress is mandatory to increase this curvature, inducing a line tension contribution [1]. After simplification, this contribution can be given as:

$$
\tau_{T L}^{s}=\max \left[\frac{\alpha^{s} \mu b}{\lambda^{s}-l_{c}}-\tau_{e f f}^{s}, 0\right] .
$$

At high temperature where the effective stress becomes negligible and the average obstacle spacing $\lambda$ equals $1 / \sqrt{\rho_{o b s}}$ (see eq. 9), $\tau_{L T}$ recovers its well-known expression:

$\tau_{T L}^{s}=\alpha^{s} \mu b \sqrt{\rho_{o b s}^{s}}$,

known as the Taylor equation. 


\subsection{Introducing radiation defects}

Assessment of radiation hardening at the grain scale has received a large attention from the scientific community, see for example [17]. Different approaches have been proposed ranging from detailed interaction description (see for ex. [27]) to more or less phenomenological treatments [28,29]. The common feature of these models is the assumption that radiation hardening at the macroscopic scale is proportional to the increase in the critical stress due to interaction with radiation. Given the order of magnitude of radiation hardening, this assumption may be realistic in irradiated annealed austenitic steels, but can hardly be justified in the case of RPV steels [19].

Typical sizes of radiation defects are within few nanometers, which is quite comparable to the size of dislocation cores [30,31]. This confirms that classical elasticity theory is not always appropriate to predict the interaction strength or outcome. MD simulations are thus needed to track the interaction details and quantitatively characterize the defects resistance at the atomic level. In principle, these results can be used to implement appropriate interaction rules at larger scale simulations, such as DD simulations. Unfortunately, the majority of MD simulations aimed at the rationalization of the obtained results by tracking the details of the interaction mechanisms. In other terms, very rare attempts were made to analyze MD results at the continuum level, see for example the treatments in [32,33]. In some of these attempts, the classical cusp angle concept [34] is used to quantify directly the defects strength (ex. [35]) following the Russell-Brown model [36] (ex. [37]). However, as discussed in [38], this method is of little help in describing interactions with radiation defects. One may even question the relevance of this concept in the case of any defect of finite size. In our model, we use alternatively the concept of obstacle shear resistance, that has been used to describe interactions with voids [39,40] and other precipitates [38]. It has been shown that implementing this resistance as a local rule in DD simulations is straightforward. Applying this concept in massive DD simulations of dislocation interactions with spherical precipitates allows thus for a multiscale treatment. Monnet [19] presented a general framework for the treatment of precipitation hardening and proposed a constitutive equation giving precipitation hardening as a function of the precipitate size $D_{p r c}$, density $C_{p r c}$ and resistance $\Omega_{p r c}$. If SCs are considered as coherent precipitates (which has been recently confirmed in experiment by Shu et al. by [41] and in numerical simulations by Pascuet et al. [42]), application of the constitutive equation in the case of SCs gives:

$$
\tau_{S C}=\left(\frac{\Omega_{S C}}{\Omega_{\infty}} \frac{\ln \left(2 \underline{D}_{S C} / b\right)}{\ln \left(L_{S C} / b\right)}\right)^{3 / 2} \frac{\ln \left(L_{S C} / b\right)}{2 \pi} \mu b \sqrt{C_{S C} D_{S C}},
$$

with $\Omega_{S C}, D_{S C}, L_{S C}$ (not to be confused with the average length of screw dislocation segments $l_{s c}$ in eq 10) are respectively the shear resistance, size and average free planner spacing of SCs. $\underline{D}_{S C}$ is the harmonic mean of $D_{S C}$ and $L_{S C}$, which equals $\left(D_{S C} L_{S C}\right) /\left(D_{S C}+L_{S C}\right) . \Omega_{\infty}$ is the maximum resistance of $4.5 \mathrm{GPa}$ beyond which hardening saturates because dislocations cannot penetrate obstacles (Orowan mechanism). For pure $\mathrm{Cu}$ or $\mathrm{Cr}$ coherent precipitate in iron, the resistance is close to $2.3 \mathrm{GPa}$ [38]. But recent MD simulations [42] have shown that $\Omega_{S C}$ is rather close to $2.8 \mathrm{GPa}$. In the rigorous treatment, $L_{S C}$ is equal to [ $\left(D_{S C} C_{S C}\right)^{-0.5}-D_{S C}$, but since the average spacing is significantly larger than the size, $L_{S C}$ reduces to $\left(D_{S C} C_{S C}\right)^{-0.5}$, which explains the presence of the square root in eq. 16. Comparing eq. 16 with the classical form of hardening, $\tau_{S C}=\mu b \sqrt{a_{S C} \rho_{S C}}$, it is easy to identify an appropriate value of the interaction coefficient $a_{S C}$, appearing in eq. 6. It is also easy to check that for low to 
intermediate radiation damage $C_{S C}$ is in the order of few $10^{23} \mathrm{~m}^{-3}$, with a volume fraction below 0.005 , $a_{S C}$ does not vary much and remains approximately close to 0.04 .

Concerning hardening induced by dislocation loops, two tendencies can be isolated depending on loop size $D_{D L}$ [43]. Interaction with large loops is similar to dislocationdislocation interactions (shearing, junction annihilation, etc.). This population's contribution is thus similar to the forest contribution. However, loops of size less than $4 \mathrm{~nm}$ are absorbed by the edge character, leaving a super-jog, while a helical turn is formed on screw dislocations inducing a high pinning force. Massive DD simulations were performed to compute hardening due to the absorption mechanism [44]. It was shown that for dislocation loops of $2-4 \mathrm{~nm}$ size and of density up to $10^{23} \mathrm{~m}^{-3}$, a simple Taylor-type equation reproduces all DD simulation results within a good accuracy:

$\tau_{D L}^{s}=0.5 \mu b \sqrt{D_{D L} C_{D L}}$

Again, comparing eq. 17 with $\tau_{D L}^{s}=\mu b \sqrt{a_{D L} \rho_{D L}}$, it is possible to identify a value of $a_{D L}=$ 0.25 that can be used in eq.6. The contribution of DLs to hardening was recently reviewed in [19] and it was shown that the induced hardening as revealed by DD simulations is quite similar to that induced by network dislocations, using the same scaling parameters (average distance between dislocation lines) and interaction strength.

\subsection{Implementation of slip activity on $\{112\}$ planes}

In the initial CL [1], slip was constrained on $\{110\}$ planes, generating 12 slip systems. However, many experimental results (see for ex. [45]) evidenced the activity of other slip planes, at least the $\{112\}$ planes. This missing feature did not affect results in [1] because the simulated behavior concerned only orientations in the center of the standard stereographic triangle, implying a primary and a secondary slip plane of $\{110\}$ type [46].

But activity on the $\{112\}$ planes may play an important role in the deformation of polycrystals such as RPV steels, because increasing the number of slip systems induces a decrease in the Taylor factor [47]. In the following we present the method used to implement this feature in the CL.

The activation energy in eq. 3 has been fitted on experimental data of slip activity on the $\{110\}$ planes. This is the easy part because $\{110\}$ planes are the principal slip planes in BCC metals $[48,49]$. Much less experimental data are available on the activation parameters for slip on the $\{112\}$ planes. Spitzig and Keh [50,51] measured the flow stress as a function of the tensile axis orientation. At all test temperatures, the CRSS of Fe single crystals can be sorted as $\tau_{110}<\tau_{112-\mathrm{TW}}<\tau_{110-\mathrm{AT}}$, where $\tau_{110}, \tau_{112 \text {-TW }}$ and $\tau_{110-\mathrm{AT}}$ are the CRSS on the $\{110\}$, $\{112\}$ in the twining direction and $\{112\}$ (in the anti-twining direction) respectively. They have also shown that the CRSSs on the different planes scale with different values of the parameter $\tau_{\mathrm{o}}$ in eq. 3 . In this paper, we adopt the same strategy in accounting for the activity on the $\{112\}$ planes. We thus consider the same value of $\Delta G_{o}$ and different values for $\tau_{0}: 360$ $\mathrm{MPa}$ (for the $\{110\}$ planes), $410 \mathrm{MPa}$ (for the $\{112\}$ planes in the twinning direction) and $480 \mathrm{MPa}$ (for the $\{112\}$ planes in the anti-twining direction).

Another important feature must be highlighted. The interaction coefficients between the $\{110\}$ and $\{112\}$ planes must account for the relaxation induced by the cross slip of screw dislocations between the two plane families. This relaxation is not considered in the classical representation of interaction coefficients. In fact, since during cross slip the two activated slip systems share the same Burgers vector, the resulting interaction is considered to be of 
collinear type, that is, the strongest interaction. Consequently, instead of considering the collinear interaction coefficient (which amounts to $a_{c o l}=0.7$ ), we propose to use a new coefficient, called the Cross-slip coefficient $\left(a_{\mathrm{cs}}\right)$ with a strength equal to that of the selfinteraction $\left(a_{s c}=a_{\text {self }}=0.1\right)$. The total interaction matrix with the reference values of the different interaction coefficients (in the inset table) are given in Figure 1.

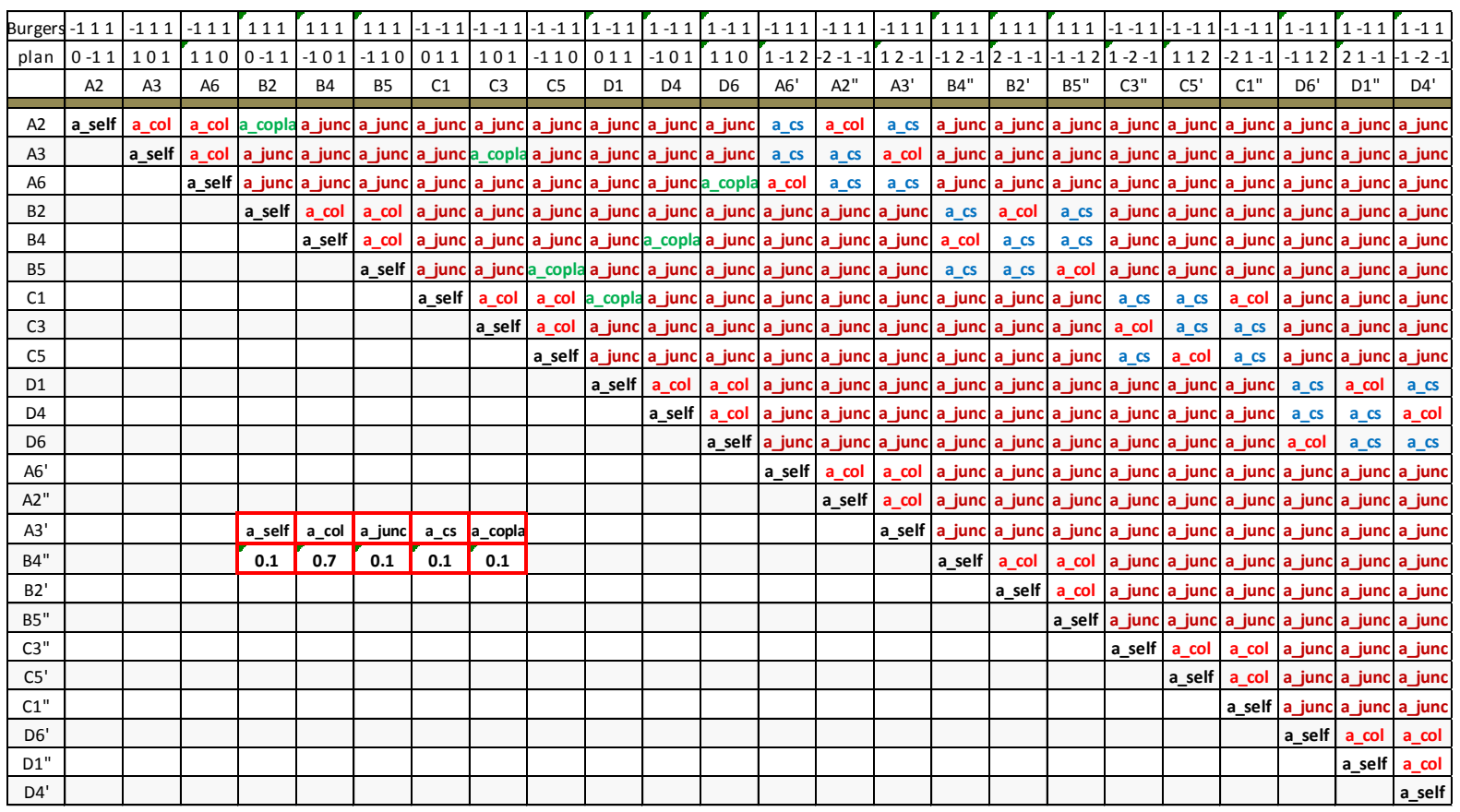

Figure 1: Interaction matrix of slip systems on the $\{110\}$ and $\{112\}$ planes with the reference values.

For the sake of simplicity, only two values of the coefficients are used: 0.7 for the collinear interaction and 0.1 for all the others. In our model we do not distinguish the cross-slip between the $\{110\}$ planes and the $\{112\}$ in the twinning direction from that in the antitwinning direction.

\subsection{Evolution of defects densities}

A classical Kocks-Mecking formulation [52] is used to predict the evolution of dislocation densities as a function of plastic glide:

$$
\frac{\dot{\rho}^{s}}{\left|\dot{\gamma}^{s}\right|}=\frac{1}{b}\left[\frac{1}{\Lambda^{s}}-y^{s} \rho^{s}\right],
$$

where $\Lambda$ represents the so-called dislocation mean free path, namely the average displacement of mobile dislocations before immobilization, and $y$ a distance below which dislocation annihilation is systematic. As explained in [1], Temperature dependent interaction statistics affect $\Lambda$ and $y$, which can be accounted for by the following expressions:

$$
\frac{1}{\Lambda^{s}}=\frac{1}{d_{\text {grain }}}+\left(1-\frac{\tau_{\text {eff }}^{s}}{\tau_{o}}\right)\left(\frac{\sqrt{a^{\text {self }} \rho^{s}}}{K_{\text {self }}}+\frac{\alpha^{s} \lambda^{s} \rho_{o b s}^{s}}{K_{o b s}}\right),
$$




$$
\frac{1}{y^{s}}=\frac{1}{y_{\text {drag }}^{s}}+\frac{2 \pi \tau_{e f f}^{s}}{\mu b} .
$$

Where $K_{\text {self }}\left(K_{o b s}\right)$ are constants representing the number of intersections with primary dislocations (local obstacles) before immobilization. They correspond to the permeability of primary dislocations (obstacles) to dislocation crossing and $y_{\text {drag }}$ is the annihilation distance that prevails at high temperature in the drag regime.

Since radiation defects are usually sheared, one must also account for the evolution of the local density of these defects. Consider interactions with $D L s$ of size $D_{D L}$. Let $V$ be a small volume subjected to a shear increment $d \gamma$. The latter must equal $b d S / V$, where $d S$ is the area swept by dislocations. If we consider that a moving dislocation can drag or absorbe all loops contained in a layer of thickness $\left(\lambda_{D L} D_{D L}\right)$, centered on the dislocation slip plane, then the decrease in the loop density on system $s$ within the volume $V$ is simply $d C_{D L}=$ $\lambda D_{D L} d S C_{D L} / V$. Combining $d \gamma$ and $d C_{D L}$ and dividing by the time increment, one gets :

$$
\dot{C}_{D L}^{s}=-\lambda_{D L} \frac{D_{D L}^{s}}{b} C_{D L}^{s}\left|\dot{\gamma}^{s}\right|
$$

The parameter $\lambda$ accounts for the efficiency of the dislocation in dragging the loops. By definition, when $\lambda=1$, only loops cutting the slip plane are absorbed.

A similar reasoning can be applied to SCs. The softening here results from shearing rather than dragging or absorption. We may write:

$$
\dot{C}_{S C}^{s}=-\lambda_{S C} \frac{D_{S C}^{s}}{b} C_{S C}^{s}\left|\dot{\gamma}^{s}\right|
$$

Of course, in the case of SCs, there is no reason that $\lambda_{S C}$ can be larger than one. On the contrary, we expect the SCs to be completely sheared after the passage of $n=D_{S C} / \mathrm{b}$ dislocations. In other terms, a plausible value for this parameter would be $\lambda_{S C}=1 / n=\mathrm{b} / D_{S C}$, which allows to simplify eq. 22 to :

$$
\dot{C}_{S C}^{s}=-C_{S C}^{s}\left|\dot{\gamma}^{s}\right|
$$

However, this equation questions the relevance of the cross graining (scale transition) procedure used here, that is, the transition from the dislocation discrete space to the continuum space of larger scale simulations such as finite-element method.

\section{Simulation of the macroscopic behavior}

\subsection{Simulation methods}

In this work, three simulation techniques for the integration of the crystalline law have been used: the classical self-consistent homogenization scheme with the Berveiller-Zaoui localization rule [53], called in the following the BZ method, and two full field simulation techniques: the Finite Element (FE) method using the code CAST3M [54] and the FFT based solver AMITEX-FFTP [55], called FFT method. The BZ method was used in all the applications below, while the FE method was used for the tensile simulations of single crystals and the FFT method for the simulations of tensile tests of RPV steels. 
FFT-based simulations have been performed on Voronoï cubic grain aggregates, with various spatial resolutions and various number of grain orientations (taken from a random isotropic crystallographic texture). Finally, the converged average behavior of the Voronoï polycrystal obtained with 1000 orientations and a spatial resolution of $7 \times 7 \times 7$ voxels per grain was found to be satisfactorily reproduced with a much simpler cubic grain aggregate, with 125 grains and one voxel per grain, leading to drastically reduced computation times, comparable to the BZ model.

Note also that, in the following, the $\mathrm{BZ}$ and FE simulations use the small strain approximation whereas FFT simulations use the complete finite strains framework.

In all simulations, the values of the constants and the material parameters are listed in Table 1. Of course, the parameter values depend on the tested materials.

\begin{tabular}{|l|c|l|c|}
\hline Parameter & Value & Parameter & value \\
\hline$\dot{\gamma}_{o}($ rate constant) & $10^{-5} \mathrm{~s}^{-1}$ & $n$ (rate power) & 100 \\
\hline$\Delta G_{o}$ & $0.84 \mathrm{eV}$ & $\tau_{o}(\{110\})$ & $360 \mathrm{MPa}$ \\
\hline$H$ & $210^{11} \mathrm{~s}^{-1}$ & $\tau_{o}(\{112\} \mathrm{TW})$ & $410 \mathrm{MPa}$ \\
\hline$b$ (Burgers vector) & $0.248 \mathrm{~nm}$ & $\tau_{o}(\{110\} \mathrm{AT})$ & $480 \mathrm{MPa}$ \\
\hline$E$ (Young modulus) in GPa & $236-0.0459 T$ & $k$ (Boltzmann constant) & $8.610^{-5} \mathrm{eVK}^{-1}$ \\
\hline$a^{i j}$ (non collinear) & 0.1 & $v$ (Poisson's ratio) & 0.35 \\
\hline$y_{\text {drag }}$ (dist. annihi.) & $2 \mathrm{~nm}$ & $a^{i j}$ (collinear) & 0.7 \\
\hline $\begin{array}{l}\rho_{\text {sini }}^{\mathrm{s}}=\rho_{\mathrm{m}}^{\mathrm{s}} \text { (primary system) } \\
\text { singlecrystal simulation }\end{array}$ & $10^{12} \mathrm{~m}^{-2}$ & $\begin{array}{l}\rho_{\text {ini }}^{\mathrm{s}}=\rho_{\mathrm{m}}^{\mathrm{s}}(\text { other systems }) \\
\text { singlecrystal simulations }\end{array}$ & $10^{112} \mathrm{~m}^{-2}$ \\
\hline$\rho_{\text {ini }}^{\mathrm{s}}=\rho_{\mathrm{m}}^{\mathrm{s}}$ Fe polycrystal & $10^{11} \mathrm{~m}^{-2}$ & $\rho_{\text {ini }}^{\mathrm{s}} \rho_{\mathrm{m}}^{\mathrm{s}} \mathrm{RPV}$ & $10^{13} \mathrm{~m}^{-2}$ \\
\hline$K_{\text {self }}$ & 17 & $K_{\text {forest }}$ & $K_{\text {self }} / 3$ \\
\hline$C_{\text {carbide }}(\mathrm{RPV})$ & $7.6 \times 10^{17} \mathrm{~m}^{-3}$ & $l_{c}$ (minimal length) & $10 \mathrm{~nm}$ \\
\hline$d_{\text {grain }}(R P V)$ & $6.9 \mu \mathrm{m}$ & $\lambda_{S C}$ & 0 \\
\hline$D_{\text {carbide }}(\mathrm{RPV})$ & $80 \mathrm{~nm}$ & $\lambda_{D L}$ & 0 \\
\hline
\end{tabular}

Table 1: Values of the model parameters and material constants used for the simulations

\subsection{Validation of the implementation of $\{112\}$ planes}

FEM simulations of tensile test of single crystal beam of [149] has been reported in [1]. This orientation is close to the center of the standard stereographic triangle (orientation D in the inset of Figure $2 a$ ), and activates slip on the (101) plane. Using exactly the same simulation conditions and sample geometry, we simulate using the FE method tensile tests of beams orientations [118] (close to orientation A) and [288] (close to orientation B), activating, respectively, slip on the (1 $1 \overline{1} 2)$ planes in the twinning direction and on the $(\overline{2} 11)$ plane in the antitwining direction. In these simulations of pure Fe single crystals, we set $\rho_{S C}=\rho_{D L}=$ $\rho_{\text {carbide }}=0$, with a high enough value of grain size $d_{\text {grain }}$ to suppress the Hall-Petch effect. 

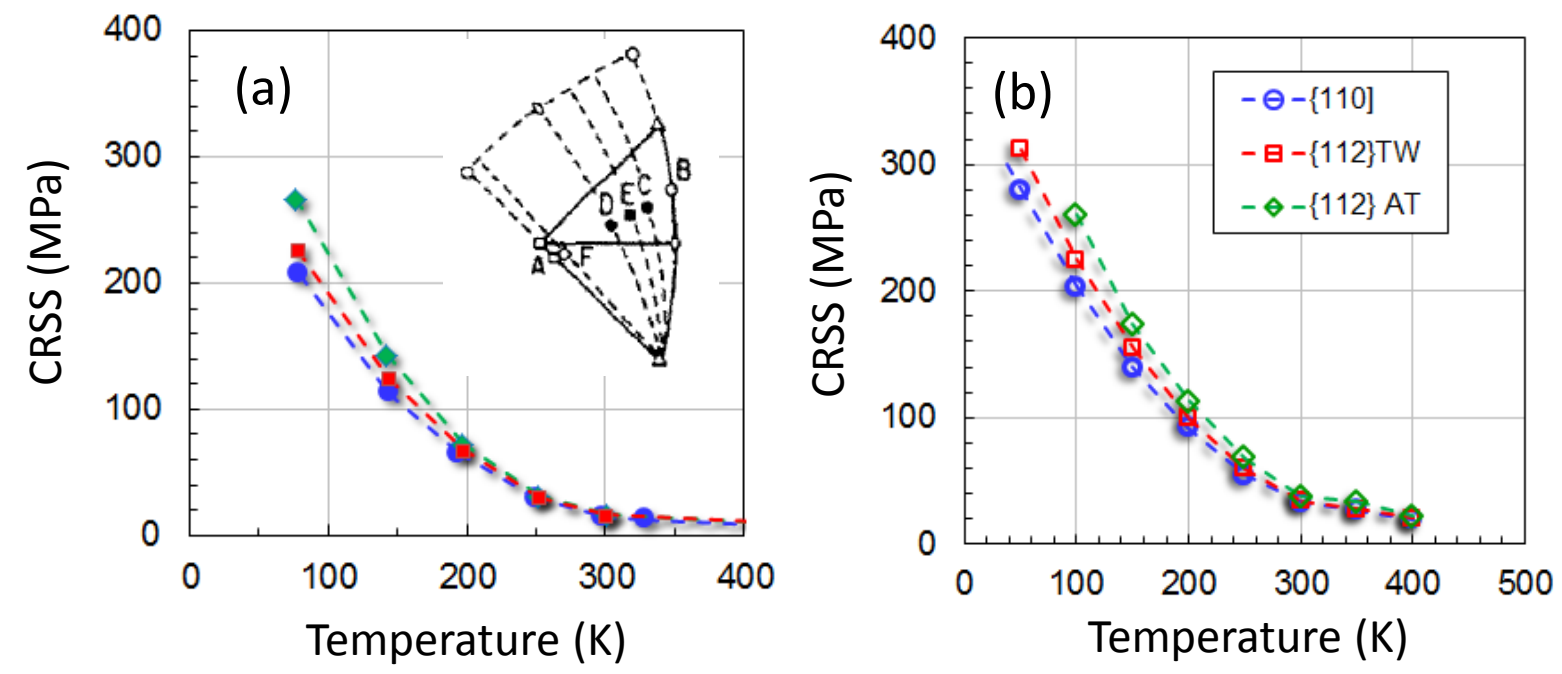

Figure 2: evolution of the critical resolved shear stress with temperature for three orientations, (a) experimental results from [50] and (b) predicted values in FEM simulations.

The comparison between the measured and computed values of the CRSS as a function of temperature and single crystal orientation is shown in Figure $2 \mathrm{a}$ and $\mathrm{b}$. At each simulation temperature, the CRSS on the (101) plane is lower than that on the (112) plane, which is also lower than that on the $(\overline{2} 11)$ plane. The obtained sorting and ratios between the different CRSS is in agreement with experimental observations [50,51]. This indicates that the implementation of slip activity on the $\{112\}$ planes meets the rare requirements reported in the literature.

\subsection{Behavior of pure iron polycrystals}

The second set of simulations was obtained using the BZ method on pure Fe polycrystals. Materials parameters are the same as above, apart from dislocation densities on the different slip systems. They were taken such that the total dislocation density is close to $10^{13} \mathrm{~m}^{-2}$. Since the conventional offset of $0.2 \%$ strain is usually affected by static aging in iron, we use stress at $2 \%$ offset of deformation to compare with experiment [56]. The evolution of the yield stress predicted by the BZ method is depicted in Figure 3. 


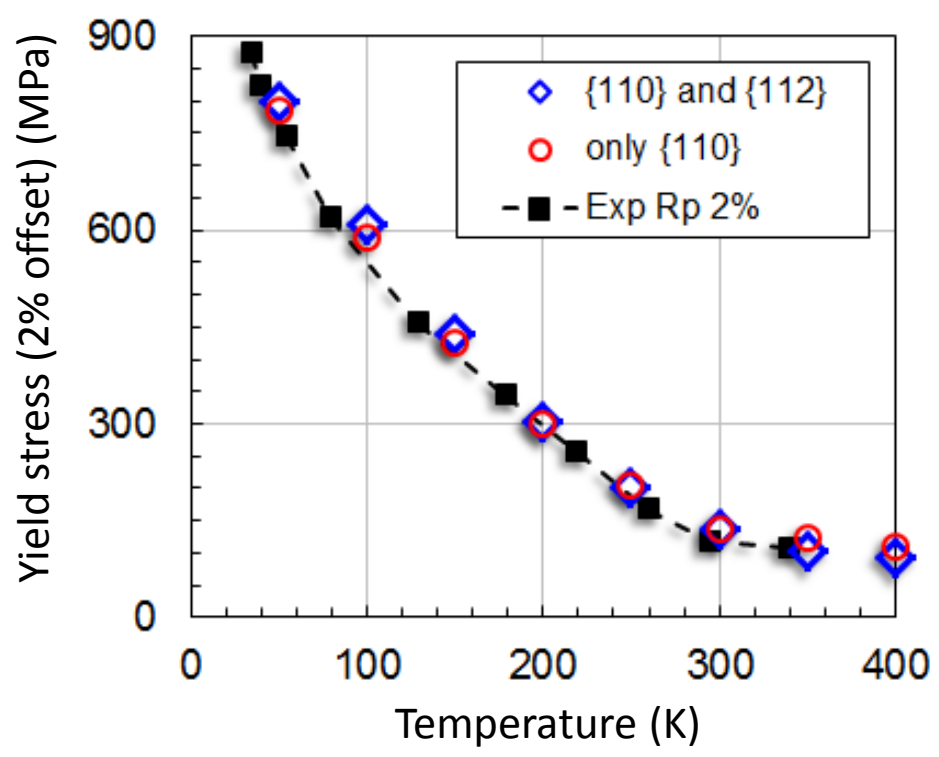

Figure 3: comparison of the yield stress at $2 \%$ strain measured in experiment and predicted by the BZ homogenization technique, using all slip planes $(\{110\}$ and $\{112\})$ and only $\{110\}$ planes.

As can be noticed from the figure, there is a good agreement with experiment in the whole temperature range. The surprising feature is that the implementation of the $\{112\}$ planes with different activation scheme does not alter strongly the predicted yield stress. Passing from 12 to 24 slip systems does not seem to soften the mechanical behavior.

\subsection{Simulated behavior of the RPV steel}

In this Section we target RPV steels with metallurgical characteristics close to those of the SA508 class specifications. For these steels, it is important to account for the intra-lath carbide density and the high dislocation density in both the un-irradiated and irradiated states. To do so, it is important to select a reference material that has been characterized using experimental tests. This material is called Euromaterial A and has been characterized in the PERFECT project [57] by Vincent et al in [58] and others [59,60]. The values of the constants found for this material can be consulted in Table 1.

The comparison between the experimental and simulated tensile curves can be seen in Figure 4. The comparison is made at three different values of temperature. The materials parameters, that is, the dislocation density, the mean free paths and the grain size are the same. It can be seen that without adjusting the crystalline law at every temperature, the predicted tensile curves are close to the experimental ones, which highlights the predictive power of the CL. 


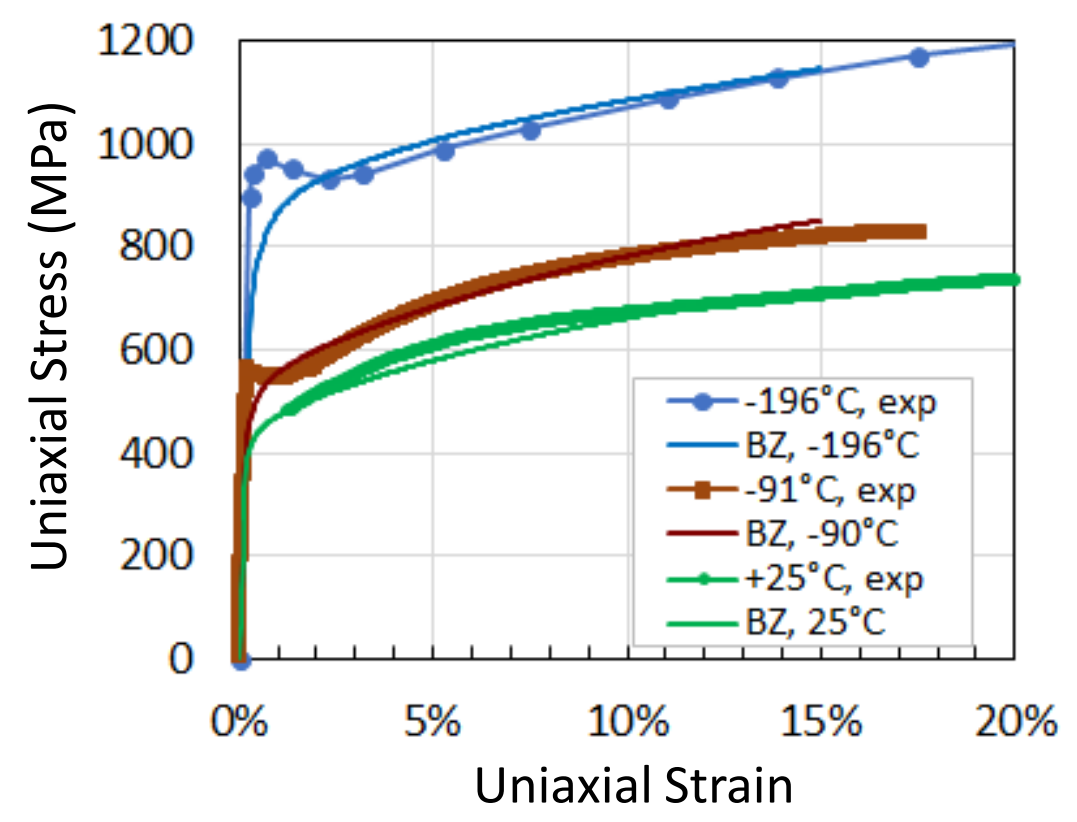

Figure 4: simulated (BZ method) vs experimental tensile curves of the RPV material Euromateriala A at three different temperatures.

However, at the onset of plastic deformation, the predicted curves are smooth and do not fit correctly the experimental curves. This feature is due to the moderate static aging, known to prevail in most of Fe-C alloys and steels [61]. The constitutive description of static aging is still a difficult task and, to the knowledge of the authors, has not been addressed deeply in the literature.

The self-consistent scheme adopted here [53] is known to be well adapted for elasto-plastic behavior. However, the BZ homogenization model is also well known to provide estimates that are too stiff (even violating bounds in some specific cases) [62,63]. Hence, it is interesting to compare the BZ self-consistent results with the ones of a full field FFT method. The two sets of simulated tensile curves are depicted in Figure 5, considering for both implementations a small strain formulation framework. It can be seen that, at the $0.2 \%$ plastic strain offset, the difference between predictions is negligible for the all tested temperatures. 


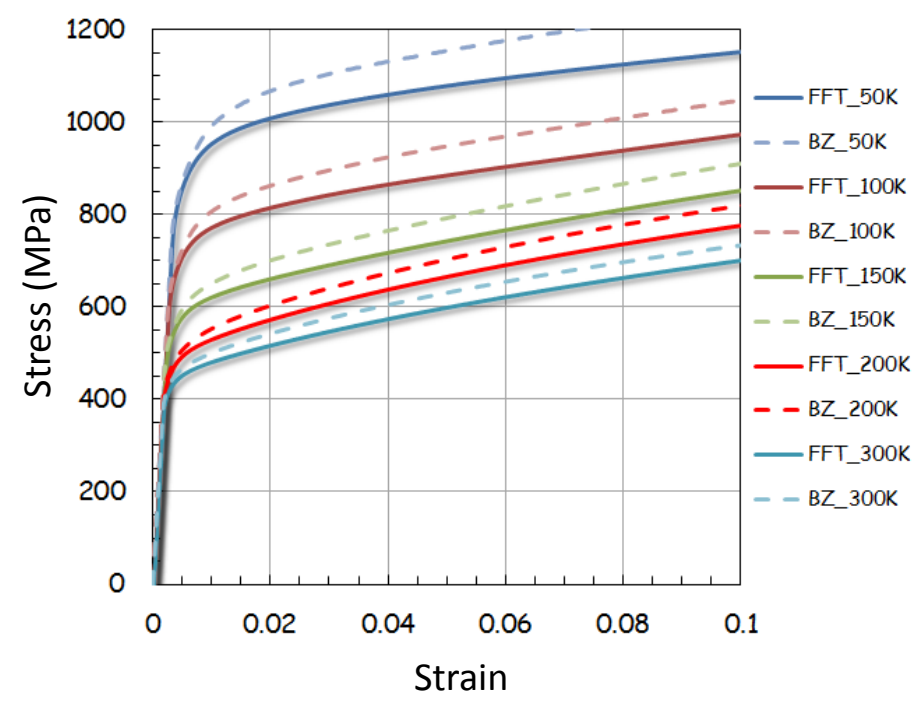

Figure 5: comparison between the tensile curves predicted by the BZ (self-consistent) and FFT (full field) methods at different temperature.

At larger strains, the BZ method is too stiff, as expected, and predicts significantly higher tensile stresses. The deviation seems to increase monotonously with the flow stress and plastic deformation. However the shift remains in the order of $5 \%$ at the offset of $2 \%$ of plastic strain. At low strain, The FFT and BZ methods provide thus consistent predictions of the flow stress, and the BZ method is used in the following for that purpose.

This result encourages us to check for the effect of solute cluster on the flow stress and internal variables of the model.

We consider the typical values of density and size of solute clusters (using APT characterization) of moderately irradiated low copper RPV steels recalled in Table 1. For the as-received (AR) materials (non-irradiated), the simulation predictions are compared with results obtained by Renevey [64], Libert [65] and Euromateriala A [58]. Radiation hardening has been measured on the Euromateriala A [58] materials. The comparison is shown in Figure 7 for all the reported results. 


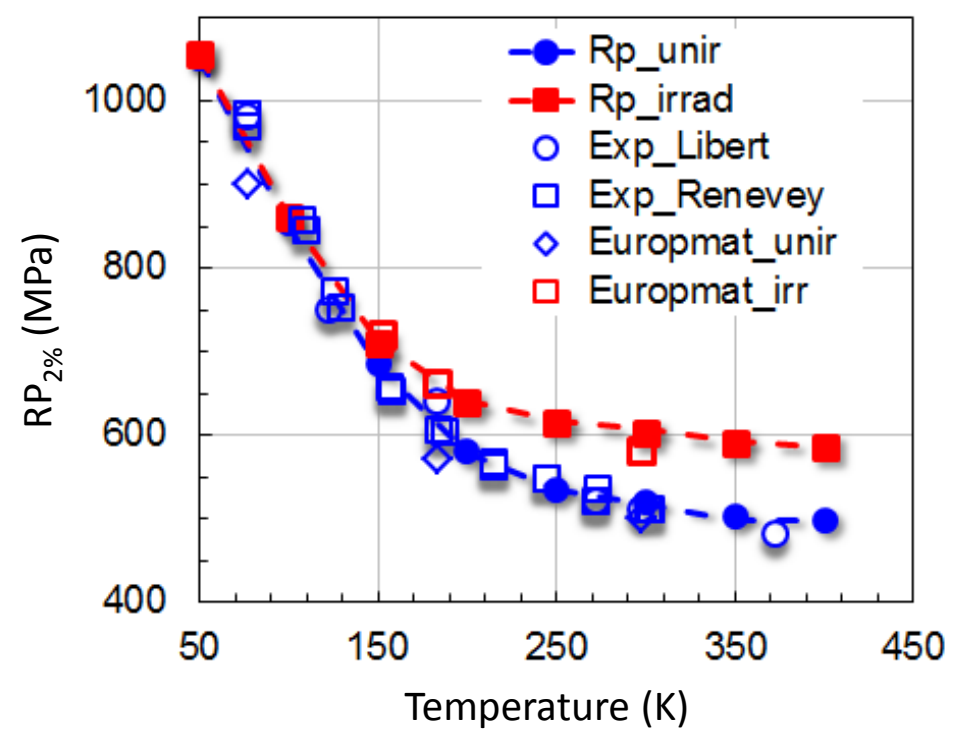

Figure 6: comparison between the BZ predictions (full symbols) and experimental values (open symbols) of the flow stress at.2\% offset strain in RPV steels before (in bleu) and after (in red) irradiation as a function of the simulation/experimental temperature of the tensile tests.

Since RPV experience static aging, especially at low temperature, we consider the flow stress at the offset strain of $2 \%$. Two important remarks can be made: (i) there is a fare agreement between experimental and simulation results in the AR and irradiated cases, obtained with no adjustable parameters and (ii) radiation hardening seems to vanish at low temperatures. Contrary to the popular belief, radiation hardening does depend on temperature. At the first glance, this appears to be in contradiction with experimental results (see for ex. [66,67]). Our interpretation of this discrepancy is that the offset of $0.2 \%$ for the measurement of the yield stress is not the most appropriate. This is due to static aging strongly accentuated by irradiation. The Lüders plateau increases with decreasing temperature and increasing radiation dose, as can be seen on Figure 4. However, according to our model, at very low temperature, the flow stress of RPV at strains larger than, say $2 \%$, must not be strongly affected by irradiation. We could not confirm this important result because we could not find available tensile curves on irradiated RPV in the literature. On the other hand, Figure 6 shows that radiation hardening is little sensitive to temperature above $300 \mathrm{~K}$. The small decrease in irradiation hardening is due to the classical elastic softening. This athermal high-temperature irradiation hardening has been discussed in details in recent papers $[4,19]$, in which radiation hardening is predicted and compared with experimental results in RPV, Fe-Cr ferriticmartensitic and austenitic stainless steels.

One of the most important parameter in our model is the evolution of the average length of screw dislocation segments $l_{s c}$. This variable delineates the domain of appearance of the line tension contribution. When, $l_{s c}$ decreases to its minimal value $l_{c}=10 \mathrm{~nm}$, the line tension contribution is no longer zero, because the fraction term in the min expression involving $\lambda$ in eq. 14 becomes larger than the effective stress. 


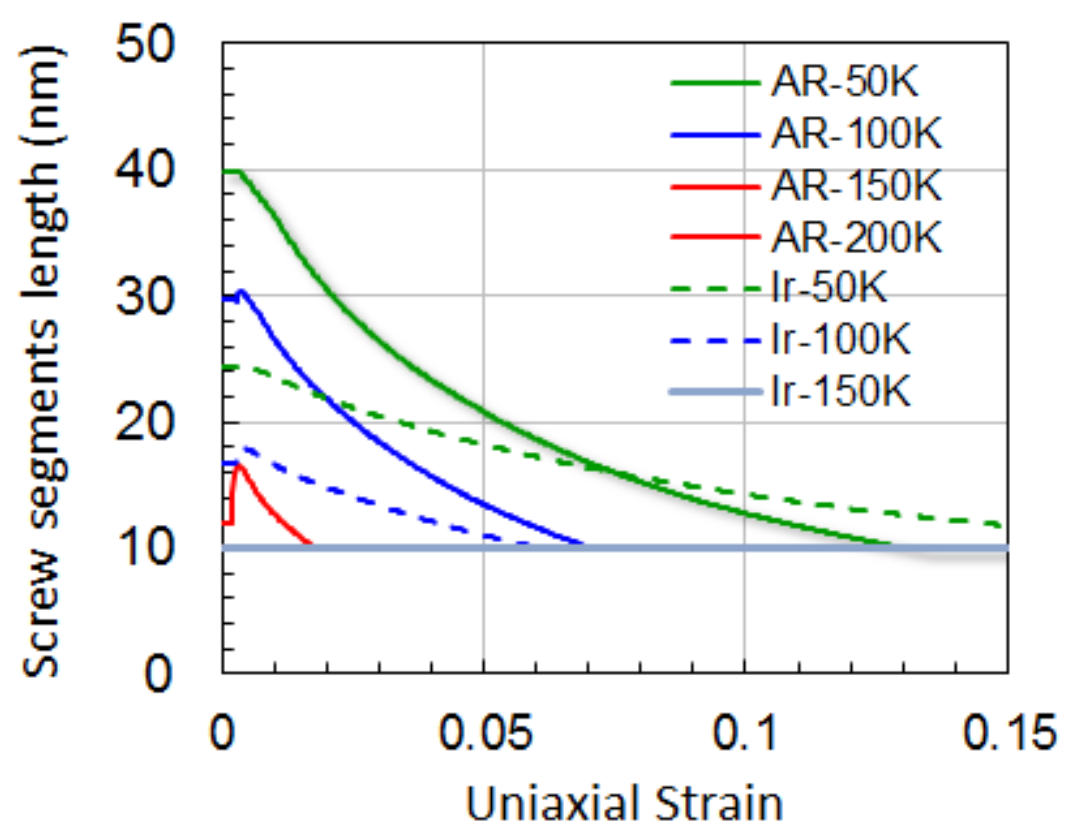

Figure 7: evolution of the average length of screw segments as a function of strain and BZ simulation temperature with (Ir for irradtaed) and without (AR for as-received unirradiated) solute clusters defects.

In order to track the evolution of $l_{s c}$ in the simulations of RPV (AR and irradiated) we choose to record the value of $l_{s c}$ associated with the most active slip system in the best oriented grain, that is, with the highest Schmid factor. This evolution is given in Figure 7 as a function of strain for different simulation temperatures in the irradiated (with solute clusters) and unirradiated case. For all profiles at larger simulation temperatures than the one plotted in the figure, $l_{s c}$ reaches its minimal value at the beginning of deformation. $l_{s c}$ is found to decease as expected with deformation because of the increase in the obstacle density, which in this case corresponds to the stored dislocations. At low temperature, $l_{s c}$ is large because the effective stress is large, which increases the curvature and the average obstacle spacing. When SCs are added as a new component of the microstructure, the same behavior is found but $l_{s c}$ is lower in irradiated materials because of the increase in the obstacle density. Consequently, the line tension contribution increases with the density of radiation defects. This is the origin of radiation hardening, which explains the insensitivity of hardening to temperature for $\mathrm{T}>300$ $\mathrm{K}$. Another interesting feature is that $l_{s c}$ in the irradiated material becomes larger than that in the unirradiated materials for uniaxial strain larger than $8 \%$, as can be noticed in Figure 7. This is a tricky property and can be explained as follows. The increase in the critical stress due to the presence of solute clusters delays the activation of secondary slip. Since $K_{\text {copla }}$ is substantially higher than $K_{\text {forst }}$, (see Table 1$)$, the mean free path of primary dislocations $\left(\Lambda^{s}\right.$ in eq. 19) decreases less with strain, which slows down dislocation storage (eq. 18) and, consequently, slows down the decrease in $l_{s c}$. Although in the irradiated material, the starting value of $l_{s c}$ is lower than in the unirradiated material, at enough strain, $l_{s c}$ in the irradiated material exceeds that in the unirradiated one.

In order to give an insight into the different contributions of the microstructure components to the flow stress, we show in Figure 8 the evolution of every contribution as a function of temperature in the unirradiated (a) and irradiated (b) RPV steels. 


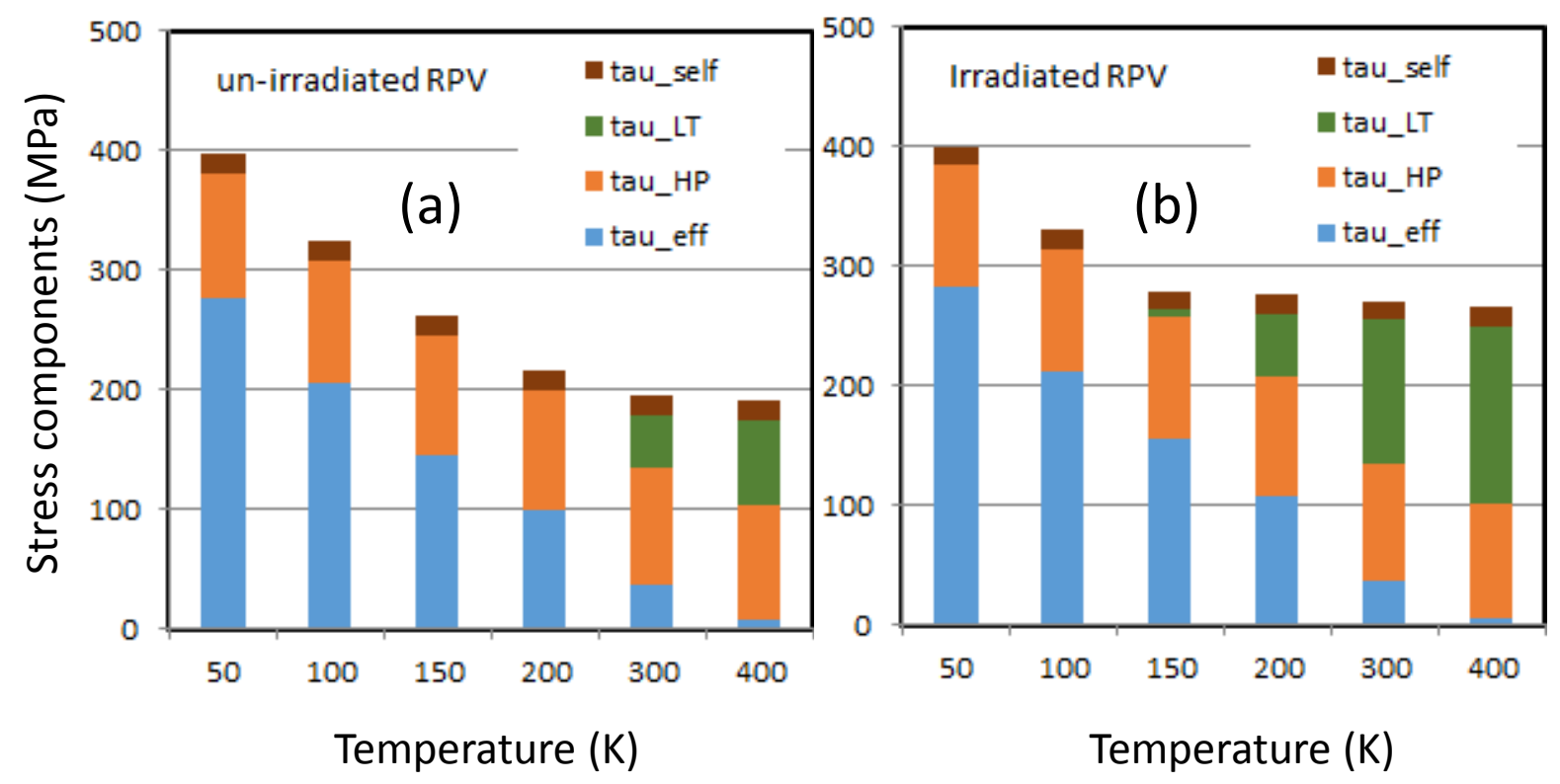

Figure 8: contributions of the microstructure components in un-irradiated (a) and irradiated (b) RPV steels as a function of temperature.

From the figure, several remarks can be made: (i) the grain size contribution (Hall-Petch effect) at high temperature amounts to more than one third of the applied stress, which confirms that the grain size effect cannot be neglected in bainitic microstructure. (ii) The effective stress depends strongly on temperature but little on radiation defects. (iii) The line tension contribution vanishes for temperatures less than $200 \mathrm{~K}(100 \mathrm{~K})$ in the unirradiated (irradiated case). (iv) The intermediate temperature regime can be characterized from the figure in the temperature range where both the line tension and effective stress contributions are significant.(v) At room temperature, the behavior is not completely athermal. (vi) Irradiation hardening at high temperature is athermal and basically due to the increase in the line tension contribution.

\section{Conclusions}

In this paper, we present physically based constitutive equations (crystalline law) designed for polycrystalline iron and RPV steels that accounts for the thermally activated (below 250 $\mathrm{K}$ ) and athermal (above $350 \mathrm{~K}$ ) regimes, with a smooth transition in the intermediate temperature range. The flow stress is expressed in terms of the microstructural components: dislocation network, carbides, grain size and, in the case of irradiated RPV, solute clusters. This law has been integrated using the self-consistent method (using the Berveiller-Zaoui localization rule) and the full field methods: the FFT (AMITEX) and Finite-Elements (CASTEM) solvers. From the results reported in this paper, we can draw the following conclusions:

- The BZ homogenization model provides satisfying results at the onset of plastic deformation but when the applied strain increases it overestimates significantly the macroscopic response with respect to the FFT-based full field predictions, 
- For the behavior of polycrystals, it is not necessary to account for the intragranular behavior in full details. The proposed simplified law is found to reproduce appropriately the macroscopic behavior of polycrystals,

- The implementation of the $\{112\}$ slip planes does not seem to strongly affect the yield stress. No softening is obtained when passing from 12 to 24 slip systems.

- The large initial dislocation and carbide densities in RPV steels decreases strongly the average length of screw dislocation segments, which in turn increases the effective stress with respect to a fully annealed polycrystalline iron.

- Radiation defects accentuate the decrease in the screw segment length and generate a line tension contribution at lower temperatures.

- The Hall-Petch effect (grain size effect) contributes strongly to the yield stress in RPV steels. It amounts to more than $35 \%$. This component must not be neglected in modeling plastic deformation of microstructures such as bainite and martensite.

- Radiation hardening computed at $2 \%$ offset of plastic strain seems to decrease with decreasing temperature in the thermally activated regime and vanishes below $100 \mathrm{~K}$. For temperatures higher than $250 \mathrm{~K}$, hardening becomes athermal. This important feature deserves further investigation for validation at very low temperature..

\section{Acknowledgment}

The authors acknowledge the financial support of Euratom research and training program 2014-2018 SOTERIA (http://www.soteria-project.eu/) 


\section{References}

[1] G. Monnet, V. Ludovic, B. Devincre, Dislocation-dynamics based crystal plasticity law for the low- and high-temperature deformation regimes of bcc crystal, Acta Materialia. 61 (2013) 6178-6190.

[2] S. Naamane, G. Monnet, B. Devincre, Low temperature deformation in iron studied with dislocation dynamics simulations, International Journal of Plasticity. 26 (2010) 84-92. doi:10.1016/j.ijplas.2009.05.003.

[3] G. Monnet, S. Naamane, B. Devincre, Orowan strengthening at low temperatures in bcc materials studied by dislocation dynamics simulations, Acta Materialia. 59 (2011) 451-461. doi:10.1016/j.actamat.2010.09.039.

[4] G. Monnet, L. Vincent, Multiscale Modeling of Radiation Hardening, in: Handbook of Mechanics of Materials, Springer, Singapore, 2018: pp. 1-32. doi:10.1007/978981-10-6855-3_8-1.

[5] F.B. Pickering, Constitution and Properties of Steels, Vch Pub, Weinheim, 1992.

[6] N. Soneda, Irradiation Embrittlement of Reactor Pressure Vessels (RPVs) in Nuclear Power Plants, Elsevier, 2014.

[7] E.D. Eason, G.R. Odette, R.K. Nanstad, T. Yamamoto, A physically-based correlation of irradiation-induced transition temperature shifts for RPV steels, Journal of Nuclear Materials. 433 (2013) 240-254. doi:10.1016/j.jnucmat.2012.09.012.

[8] N. Soneda, K. Dohi, A. Nomoto, K. Nishida, S. Ishino, J.T. Busby, B. Hanson, S.W. Dean, Embrittlement Correlation Method for the Japanese Reactor Pressure Vessel Materials, Journal of ASTM International. 7 (2010) 102127. doi:10.1520/JAI102127.

[9] C. Teodosiu, Large Plastic Deformation of Crystalline Aggregates, CISM Courses and Lectures, Udine/Berlin, Vol 376. Springer-Verlag, 1997

[10] K. Fukuya, Current understanding of radiation-induced degradation in light water reactor structural materials, Journal of Nuclear Science and Technology. 50 (2013) 213-254. doi:10.1080/00223131.2013.772448.

[11] A. Seeger, in: Proc. 2nd UN Int. Conf. on Peaceful Uses of Atomic Energy, Geneva, Sept. 1958, Vol. 6, p. 250.

[12] B.N. Singh, A.J.E. Foreman, H. Trinkaus, Radiation hardening revisited: role of intracascade clustering, Journal of Nuclear Materials. 249 (1997) 103-115. doi:10.1016/S0022-3115(97)00231-6.

[13] S. Queyreau, G. Monnet, B. Devincre, Slip systems interactions in $\alpha$-iron determined by dislocation dynamics simulations, International Journal of Plasticity. 25 (2009) 361-377. doi:10.1016/j.ijplas.2007.12.009.

[14] R. Madec, L.P. Kubin, Dislocation strengthening in FCC metals and in BCC metals at high temperatures, Acta Materialia. $126 \quad$ (2017) 166-173. doi:10.1016/j.actamat.2016.12.040.

[15] R. Madec, B. Devincre, L.P. Kubin, From Dislocation Junctions to Forest Hardening, Phys. Rev. Lett. 89 (2002) 255508

[16] B. Devincre, L. Kubin, T. Hoc, Physical analyses of crystal plasticity by DD simulations, Scripta Materialia. 54 (2006) 741-746

[17] G.S. WAS, Fundamentals of Radiation Materials Science: Metals and Alloys, Springer, 2016. 
[18] S. Queyreau, G. Monnet, B. Devincre, Orowan strengthening and forest hardening superposition examined by dislocation dynamics simulations, Acta Materialia. 58 (2010) 5586-5595. doi:10.1016/j.actamat.2010.06.028.

[19] G. Monnet, Multiscale modeling of irradiation hardening: Application to important nuclear materials, Journal of Nuclear Materials. (2018). doi:10.1016/ j.jnucmat.2018.06.020.

[20] N.J. Petch, The Ductile-Brittle Transition in the Fracture of lensuremath\Alpha-Iron: I, Philosophical Magazine. 3 (1958) 1089-1097.

[21] H. Conrad, G. Schoeck, Cottrell locking and the flow stress in iron, Acta Metallurgica. 8 (1960) 791-796. doi:10.1016/0001-6160(60)90175-9.

[22] N. Tsuchida, H. Masuda, Y. Harada, K. Fukaura, Y. Tomota, K. Nagai, Effect of ferrite grain size on tensile deformation behavior of a ferrite-cementite low carbon steel, Materials Science and Engineering: A. 488 (2008) 446-452. doi:10.1016/j.msea.2007.11.047.

[23] R. Ebeling, M.F. Ashby, Dispersion hardening of copper single crystals, Philosophical Magazine. 13 (1966) 805-834. doi:10.1080/14786436608212698.

[24] P.B. Hirsch, F.J. Humphreys, The Deformation of Single Crystals of Copper and Copper-Zinc Alloys Containing Alumina Particles. I. Macroscopic Properties and Workhardening Theory, Proceedings of the Royal Society of London A: Mathematical, Physical and Engineering Sciences. 318 (1970) 45-72. doi:10.1098/rspa.1970.0133.

[25] Z.C. Cordero, B.E. Knight, C.A. Schuh, Six decades of the Hall-Petch effect - a survey of grain-size strengthening studies on pure metals, International Materials Reviews. 61 (2016) 495-512. doi:10.1080/09506608.2016.1191808.

[26] A. Lasalmonie, J.L. Strudel, Influence of grain size on the mechanical behaviour of some high strength materials, J Mater Sci. 21 (1986) 1837-1852. doi:10.1007/BF00547918.

27] X.J. Shi, L. Dupuy, B. Devincre, D. Terentyev, L. Vincent, Interaction of $\langle 100\rangle$ dislocation loops with dislocations studied by dislocation dynamics in $\alpha$-iron, Journal of Nuclear Materials. 460 (2015) 37-43. doi:10.1016/j.jnucmat.2015.01.061.

$28]$ C. Pokor, Y. Brechet, P. Dubuisson, J.-P. Massoud, X. Averty, Irradiation damage in 304 and 316 stainless steels: experimental investigation and modeling. Part II: Irradiation induced hardening, Journal of Nuclear Materials. 326 (2004) 30-37. doi:10.1016/j.jnucmat.2003.12.008.

[29] N. Soneda, K. Dohi, A. Nomoto, K. Nishida, S. Ishino, Development of neutron irradiation embrittlement correlation of reactor pressure vessel materials of light water reactors, (2007). http://inis.iaea.org/Search/search.aspx?orig_q=RN:39055163 (accessed June 5, 2015).

[30] G. Monnet, D. Terentyev, Structure and mobility of the edge dislocation in BCC iron studied by molecular dynamics, Acta Materialia. 57 (2009) 1416-1426. doi:10.1016/j.actamat.2008.11.030.

[31] H.A. Khater, G. Monnet, D. Terentyev, A. Serra, Dislocation glide in Fe-carbon solid solution: From atomistic to continuum level description, International Journal of Plasticity. 62 (2014) 34-49. doi:10.1016/j.ijplas.2014.06.006. 
[32] D. Rodney, Activation enthalpy for kink-pair nucleation on dislocations: Comparison between static and dynamic atomic-scale simulations, Physical Review B. 76 (2007) 144108. doi:10.1103/PhysRevB.76.144108.

[33] G. Monnet, Determination of the activation energy by stochastic analyses of molecular dynamics simulations of dislocation processes, Philosophical Magazine. 91 (2011) 3810-3829. doi:10.1080/14786435.2011.596494.

[34] J. Friedel, Dislocations, Pergamon Press, 1964.

[35] S. Patinet, L. Proville, Depinning transition for a screw dislocation in a model solid solution, Physical Review B. 78 (2008) 104109. doi:10.1103/PhysRevB.78.104109.

[36] K.C. Russell, L.M. Brown, A dispersion strengthening model based on differing elastic moduli applied to the iron-copper system, Acta Metallurgica. 20 (1972) 969974. doi:10.1016/0001-6160(72)90091-0.

[37] Y.N. Osetsky†, D.J. Bacon, V. Mohles, Atomic modelling of strengthening mechanisms due to voids and copper precipitates in $\alpha$-iron, Philosophical Magazine. 83 (2003) 3623-3641. doi:10.1080/14786430310001603364.

[38] G. Monnet, Transition methods in the multiscale simulation framework: from the atomic to the continuum scale, in: I. Ionescu, S. Bouvier (Eds.), Plasticity of Crystalline Materials: from Dislocations to Continuum, ISTE Ltd., Hoboken, NJ, 2011: pp. 3-36.

[39] G. Monnet, Y.N. Osetsky, D.J. Bacon, Mesoscale thermodynamic analysis of atomicscale dislocation-obstacle interactions simulated by molecular dynamics, Philosophical Magazine. 90 (2010) 1001-1018. doi:10.1080/14786430903117133.

[40] J. Byggmästar, F. Granberg, K. Nordlund, Molecular dynamics simulations of thermally activated edge dislocation unpinning from voids in \$lensuremath $\{$ lalpha $\$$ Fe, Phys. Rev. Materials. 1 (2017) 053603. doi:10.1103/PhysRevMaterials.1.053603.

[41] Shu_2018_Acta_FeCu_FeCuMn_APT_SANS_annealed_neutron_comparison M.I. Pascuet, E. Martínez, G. Monnet, L. Malerba, Solute effects on edge dislocation pinning in complex alpha-Fe alloys, Journal of Nuclear Materials. 494 (2017) 311321. doi:10.1016/j.jnucmat.2017.07.049

[43] D.J. Bacon, Y.N. Osetsky, D. Rodney, Dislocation-Obstacle Interactions at the Atomic Level, in: J.P. Hirth and L. Kubin (Ed.), Dislocations in Solids, Elsevier, 2009:pp. 1-90.

[44] G. Monnet, New insights into radiation hardening in face-centered cubic alloys, Scripta Materialia. 100 (2015) 24-27. doi:10.1016/j.scriptamat.2014.12.003.

[45] P. Franciosi, L.T. Le, G. Monnet, C. Kahloun, M.-H. Chavanne, Investigation of slip system activity in iron at room temperature by SEM and AFM in-situ tensile and compression tests of iron single crystals, International Journal of Plasticity. 65 (2015) 226-249. doi:10.1016/j.ijplas.2014.09.008.

[46] P.B. Jaoul, D. Gonzalez, Deformation plastique de monocristaux de fer, Journal of the Mechanics and Physics of Solids. 9 (1961) 16-18, IN1-IN2, 19-22, IN3-IN6, 23-26, IN7-IN9, 27-38.

[47] J.M. Rosenberg, H.R. Piehler, Calculation of the taylor factor and lattice rotations for bcc metals deforming by pencil glide, MT. 2 (1971) 257-259. doi:10.1007/ BF02662666 
[48] A.S. Keh, Work hardening and deformation sub-structure in iron single crystals deformed in tension at $298^{\circ} \mathrm{k}$, Philosophical Magazine. 12 (1965) 9-30. doi:10.1080/14786436508224942.

[49] T. Takeuchi, Orientation Dependence of Work-Hardening in Iron Single Crystals, Jpn. J. Appl. Phys. 8 (1969) 320. doi:10.1143/JJAP.8.320.

[50] W.A. Spitzig, A.S. Keh, The effect of orientation and temperature on the plastic flow properties of iron single crystals, Acta Metallurgica. 18 (1970) 611-622. doi:10.1016/ 0001-6160(70)90090-8.

[51] W.A. Spitzig, A.S. Keh, Orientation dependence of the strain-rate sensitivity and thermally activated flow in iron single crystals, Acta Metallurgica. 18 (1970) 10211033. doi:10.1016/0001-6160(70)90058-1.

[52] U.F. Kocks, H. Mecking, Physics and phenomenology of strain hardening: the FCC case, Progress in Materials Science. 48 (2003) 171-273. doi:10.1016/S00796425(02)00003-8.

[53] M. Berveiller, A. Zaoui, An extension of the self-consistent scheme to plasticallyflowing polycrystals, Journal of the Mechanics and Physics of Solids. 26 (1978) 325344.

[54] http://www-cast3m.cea.fr

[55] L. Gélébart, R. Mondon-Cancel, Non-linear extension of FFT-based methods accelerated by conjugate gradients to evaluate the mechanical behavior of composite materials, Computational Materials Science. 77 (2013) 430-439. doi:10.1016/ j.commatsci.2013.04.046.

[56] J.P. Cottu, J.P. Peyrade, P. Chomel, P. Groh, Etude en traction de l'adoucissement du fer de haute pureté par le carbone à basse temperature, Acta Metallurgica. 26 (1978) 1179-1188. doi:http://dx.doi.org/10.1016/0001-6160(78)90001-9.

[57] J.-P. Massoud, S. Bugat, J.-L. Boutard, D. Lidbury, S. Van Dyck, F. Sevini, PERFECT: Prediction of Irradiation Damage Effects on Reactor Components, in: G. Van Goethem, P. Manolatos, M. Hugon, V. Bhatnagar, S. Casalta, M. Deffrennes (Eds.), FISA 2006 - EU research and training in reactor systems, European Commission, Directorate-General for Research, Euratom, 2006 p. 107.

[58] L. Vincent, M. Libert, B. Marini, C. Rey, Towards a modelling of RPV steel brittle fracture using crystal plasticity computations on polycrystalline aggregates, Journal of Nuclear Materials. 406 (2010) 91-96. doi:10.1016/j.jnucmat.2010.07.022.

[59] E. Meslin, M. Lambrecht, M. Hernández-Mayoral, F. Bergner, L. Malerba, P. Pareige, B. Radiguet, A. Barbu, D. Gómez-Briceño, A. Ulbricht, A. Almazouzi, Characterization of neutron-irradiated ferritic model alloys and a RPV steel from combined APT, SANS, TEM and PAS analyses, Journal of Nuclear Materials. 406 (2010) 73-83. doi:10.1016/ j.jnucmat.2009.12.021.

[60] M. Lambrecht, E. Meslin, L. Malerba, M. Hernández-Mayoral, F. Bergner, P. Pareige, B. Radiguet, A. Almazouzi, On the correlation between irradiation-induced microstructural features and the hardening of reactor pressure vessel steels, Journal of Nuclear Materials. 406 (2010) 84-89. doi:10.1016/j.jnucmat.2010.05.020.

[61] G. Krauss, Steels: Processing, Structure, And Performance, ASM International, Materials Park, Ohio, 2005.

[62] Gilormini P. (1996) A Critical Evaluation for Various Nonlinear Extensions of the Self-Consistent Model. In: Pineau A., Zaoui A. (eds) IUTAM Symposium on 
Micromechanics of Plasticity and Damage of Multiphase Materials. Solid Mechanics and its Applications, vol 46. Springer, Dordrecht

[63] R. Masson, M. Bornert, P. Suquet, A. Zaoui, An affine formulation for the prediction of the effective properties of nonlinear composites and polycrystals, Journal of the Mechanics and Physics of Solids, Volume 48, Issues 6-7, 2000, Pages 1203-1227

[64] S. Renevey, Approches globale et locale de la rupture dans le domaine de la transition fragile- ductile d'un acier faiblement allié, Paris XI Orsay, 1997.

[65] M. Libert, C. Rey, L. Vincent, B. Marini, Temperature dependent polycrystal model application to bainitic steel behavior under tri-axial loading in the ductile-brittle transition, International Journal of Solids and Structures. 48 (2011) 2196-2208. doi:10.1016/j.ijsolstr.2011.03.026.

[66] J.A. Williams, C.W. Hunter, Irradiation Strengthening and Fracture embrittlement of A533-B Pressure Vessel Steels plate and submerged-arc weld., ASTM Special Technical Publication. (1972) 5-16.

[67] C.W. Hunter, J.A. Williams, Fracture and tensile behavior of neutron-irradiated A533-B pressure vessel steel, Nuclear Engineering and Design. 17 (1971) 131-148. doi:10.1016/0029-5493(71)90045-8. 